This document is the accepted manuscript version of the following article:

Mikhailenko, P., Ataeian, P., \& Baaj, H. (2020). Extraction and recovery of

asphalt binder: a literature review. International Journal of Pavement Research

and Technology, 13, 20-31. https://doi.org/10.1007/s42947-019-0081-5

\title{
Extraction and Recovery of Asphalt Binder: A Literature Review
}

A literature review was conducted on the main aspects of asphalt binder extraction and recovery: i) extraction methods, ii) recovery methods and iii) solvents. The extraction methods include centrifuge, reflux and vacuum and others with particular focus on their effectiveness in dissolving the binder and the potential to modify it. Studies found that the centrifuge was a relatively safe cold extraction method that was fairly effective. For the recovery methods, the rotary evaporator was found to have a good reputation for relative ease of use and less binder modification than for the Abson method. The most commonly used solvents n-propyl bromide and chlorinated solvents, while being reusable, both had reported issues of ineffectiveness as well as major concerns about user safety. Bio-sourced solvents were found to be seldom used and required higher quantities. The study concluded that more research needed to be done in developing solvents.

Keywords: asphalt binder testing, extraction, recovery, solvent, RAP

\section{Introduction}

For quality control (QC), quality assurance (QA) and research purposes, asphalt binder needs to be evaluated for its properties. For a number of tests on the properties of asphalt binders in the pavement, such as asphalt binder content, Dynamic Shear Rheology (DSR, AASHTO T 315 [1]), softening point (ASTM D 36 [2]), penetration (ASTM D 5 [3]), bending beam rheology (AASHTO T 313[4]), forensic investigations, sample integrity, antistripping, hot-in place recycling, the binder needs to be separated from the aggregates, or in other words, recovered from the mixture [5].

The need to extract and recover asphalt binder is increasing with evolving environmental concerns and technological innovations, which has resulted in widespread use of Reclaimed Asphalt Pavement (RAP) [6]. While RAP allows for the reduction of the environmental footprint of asphalt pavement [7], the variability of the RAP depending on the source presents challenges [8], and this variability manifests 
itself in the binder especially [9]. To maximize the benefit of using RAP, the properties of the recycled material, such as the aggregate and binder should be characterized and considered for the design of the mix, and this requires the use of extraction and recovery techniques [10].

Asphalt binder content influences pavement stiffness, strength, durability, fatigue life, raveling, rutting, and moisture damage performance [11,12], making it an important parameter in the QC/QA process, pavement forensic investigations and research of asphalt mixtures. There are several methods to measure the asphalt binder content and aggregate gradation such as solvent extraction, nuclear asphalt content gauge (NAC), pycnometer method, automatic recordation [13], and the ignition method [14]. However, the only series of methods that allow determining the asphalt binder content and subsequently characterizing the asphalt binder itself is binder extraction and recovery [15].

A primary concern in solvent-based asphalt binder extraction and recovery process is whether or not the various extraction and recovery methods - and also various solvent types used in these methods - affect binder properties, especially the hardening of asphalt binder $[16,17]$. The effect of solvent being present in the recovered asphalt binder or the effect of over-heating of asphalt binder during recovery process can change the stiffness of the binder [18].

As with RAP, the increasing use of polymer modified asphalt (PMA) binder has presented challenges with characterization. This is due to the difficulty of many solvents used in the extraction process in dissolving the more complex polymer molecular structures [19]. Recycled asphalt shingles (RAS) present similar issues in recovering the binder [20,21], as well as asphalt with crumb rubber added [22]. Finally, extraction and 
recovery poses challenges from the perspective of operator and environmental safety from both the apparatus and the solvents used [18,23].

The extraction and recovery of asphalt binders is commonly used by many laboratories for asphalt research and QC/QA purposes. However, the varied setups for the extraction and recovery apparatuses provide different testing times, use of laboratory resources, ease of use and performance results, heat, methods of agitating the mixture, and allowable solvents [24]. Additionally, some methods, like the Abson recovery method, depend heavily on the skill of the operator for consistent results [25].

The following literature review gives a broad view of different extraction and recovery methods along with the use of various solvents from the point of view of performance, ease of use, environmental and operator safety. This review explored factors that affect the extracted and recovered binders, identifying advantages and disadvantages of these various methods with the goal of approximating the current best methods of extraction and recovery of asphalt binders and recommending potential improvements in the field.

\section{Extraction Methods}

The solvent extraction of asphalt binder is performed for quantitative determination of binder content in specification acceptance, service evaluation, QC/QA and research purposes. The extracted aggregate can also be evaluated for its gradation and mineralogical properties.

\section{Extraction Methods and their Effects}

The ASTM D 2172 [26] standard for "Quantitative Extraction of Bitumen from Bituminous Paving Mixtures" presents the following extraction methods:

- Centrifuge method (Method A) 
- Reflux method (Methods B, C \& D)

- Vacuum method (Method E)

These differ in their use of heat, method of agitating of the mixture, and solvent types $[18,27]$. Among the five methods mentioned in ASTM D2172, the centrifuge (method A) and reflux method (Method B) are the most popular with transportation agencies due to their practical simplicity. An improvement on these was attempted with the introduction of the US Strategic Highway Research Program 'SHRP method'. It is also possible to use multiple extraction methods to achieve a more thorough extraction. Finally, some researchers have introduced automatic extraction methods with the goal of improving user safety and the consistency of results [28].

\section{Centrifuge Extraction}

Centrifuge extraction (Figure 1) is a cold method for the extraction and determination of the binder content in mixtures, and is described in ASTM D 2172, EN 12697-1 [29] and AASHTO T 164 [30]. The removal of the asphalt binder is accomplished by submerging a loose HMA sample in the solvent to let the solvent disintegrate the asphalt. The centrifuge then separates the solvent and binder mixture from the aggregates. The solvent and binder mixture is collected in a separate container, while the aggregates stay in the bowl. When fibres are used in the asphalt mix they are also collected in the bowl. 


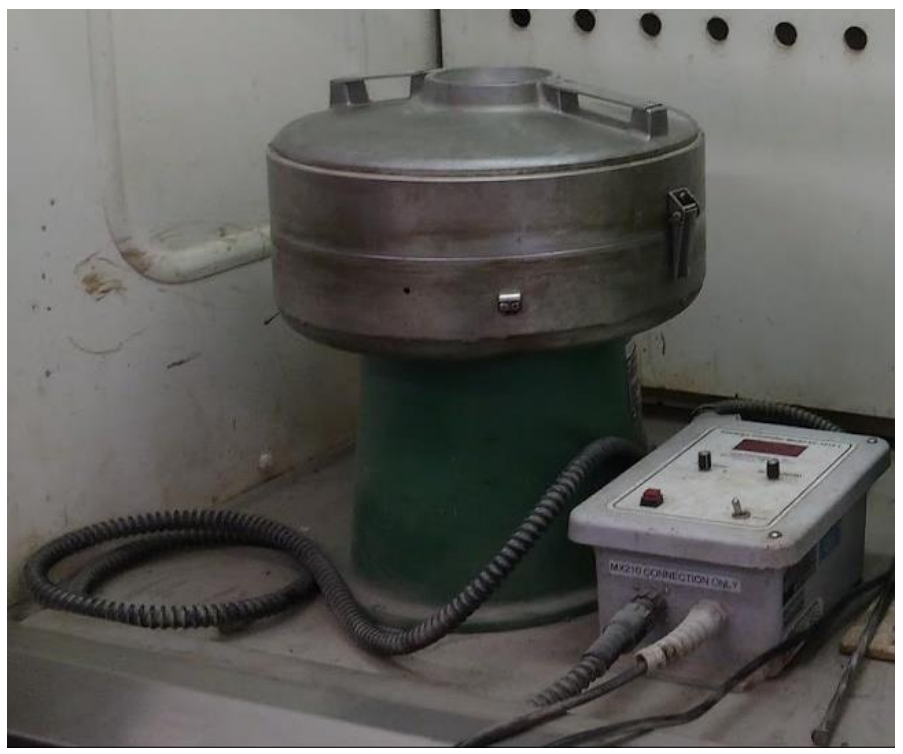

Figure 1. Centrifuge Extraction

In the Standard Test Method for Recovery of Asphalt From Solution by Abson Method (ASTM D 1856 [31]), it has been mentioned that the Centrifuge method is preferable in the case of RAP, because there is evidence that the recovered asphalt may have slightly higher penetration values compared to the values obtained by hot extraction methods, indicating less aging. This is especially important when the binder needs to be recovered after the extraction $[15,32]$, and is safer for the user due to avoiding dangerous temperatures in other methods.

In terms of drawbacks, the binder content determination was found to be less accurate compared to the Reflux method. The precision of the binder content for the Centrifuge was affected especially when using absorptive aggregates [33]. Mehta et al. (2012) found that the Centrifuge method leaves up to $4 \%$ of the total asphalt binder on the reclaimed aggregate and also concluded that it would be less desirable when the purpose of extraction is to find the asphalt content [34].

Piérard (2011) described challenges when using Centrifuge extraction with Polymer Modified Asphalt (PMA) containing Styrene-Butadiene-Styrene (SBS) and Ethylene- 
Vinyl Acetate (EVA). Solvents compatible with PMAs, such as toluene, and a longer extraction time are needed for certain PMAs [35]. Using a hot method may be preferable when only extraction is needed. On the other hand, the Centrifuge was noted for being adequate in determination of binder content for pigmented and bio-sourced binders [19], which is important as more pigmented [36] and bio-sources binders [37] are gaining interest in terms of both environmental and advancing pavement technology aspects.

\section{Reflux Extraction}

Reflux extraction (ASTM D 2172 and AASHTO T 164) is a hot extraction method. Out of the Reflux methods in ASTM D 2172, B is by far the most prevalent one [38], and is the one cited in scientific publications. The apparatus for Method B (Figure 2) consists of a glass jar, cylindrical metal frames, a condenser, filter paper, heat resistant-coated wire mesh, and electric hot plate. Solvent vapor generated by the hot plate passes around and through the asphalt mixture sample contained in two wire mesh cones lined with filter paper. The reflux solvent from the water-cooled condenser percolates through the sample repeatedly until the binder is extracted, with the solventbinder solution condensing at the bottom. 


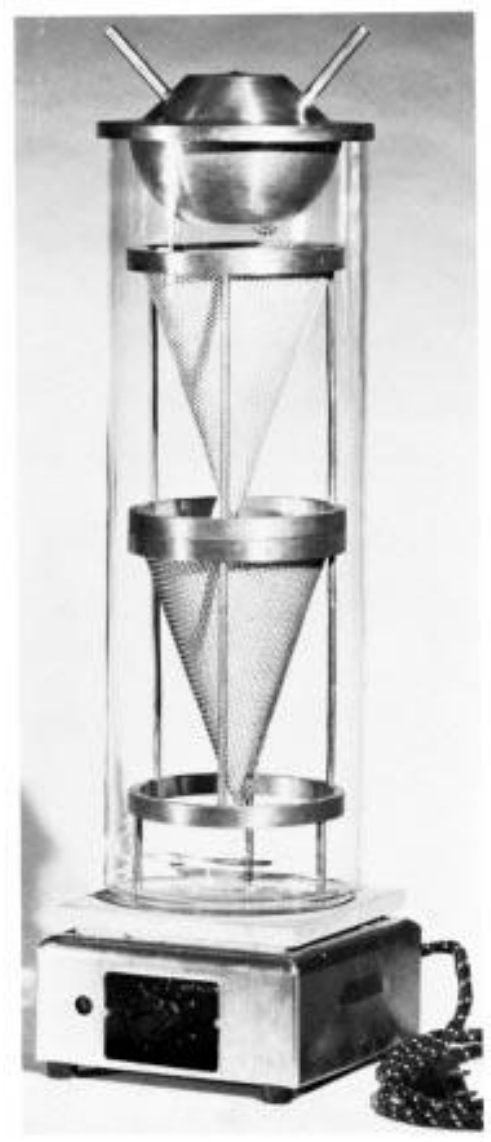

Figure 2. Reflux Extraction Method B (ASTM D 2172)

The Reflux Method B has been noted for its simplicity [39] and effectiveness in removing the binder $[11,40]$, it has also been shown that the Reflux method causes an aging effect on the asphalt binder, making it stiffer [16,27]. This is attributed to the high temperatures and fairly long exposure time to the solvent [32], but is most likely the former.

It has been suggested that Reflux extraction should not be used when the aim of the extraction is to evaluate the asphalt properties and should be used only for the determination of asphalt content and aggregate gradation [16], where it has been found to produce consistent results $[25,33]$. Nevertheless, it may also be necessary to use this method in the case of certain PMAs such as EVA, where it is more difficult to extract the binder, and additional extraction may be employed during the binder dissolution 
process [12]. In the case of asphalt with crumb rubber however, it was found to have difficulties as the crumb rubber tended to remain on the filter paper [22].

Reflux Methods C (Figure 3) and D (Figure 4) use a similar principal of vaporizing and condensing solvent, where the solvent is vaporized and makes contact with the asphalt mixture sitting on a mesh, and then allowed to condense at the bottom of the apparatus. Method $\mathrm{C}$ uses an extraction basket (mesh) in a round cooking pot that is heated while Method D has the mesh in a rectangular cabinet like apparatus. 

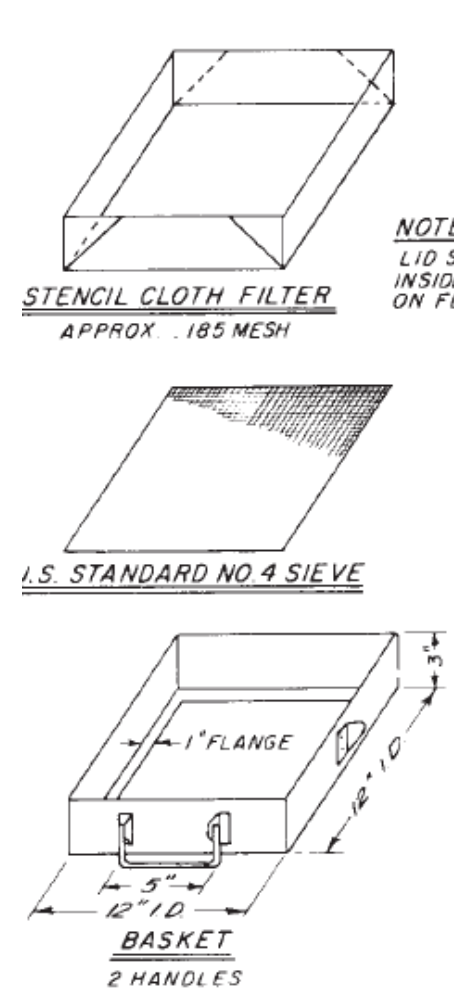

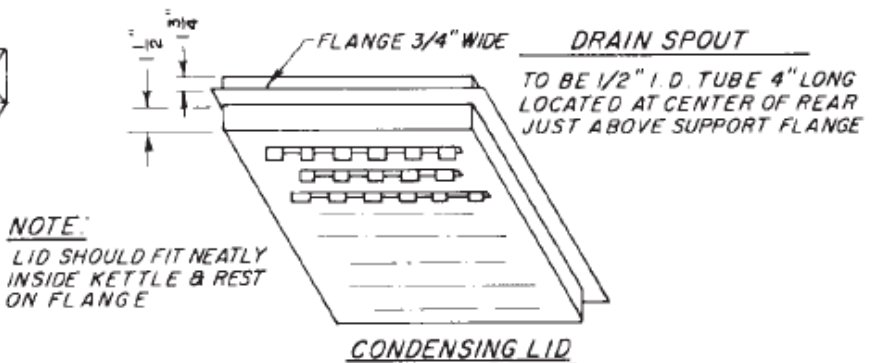

TO HAVE IOROWS OF FINS, II FINS TO A ROW FINS TO BE I/2"SQ. WITH 3/B" SPACING STAGGER FINS IN ALTERNATE ROWS.

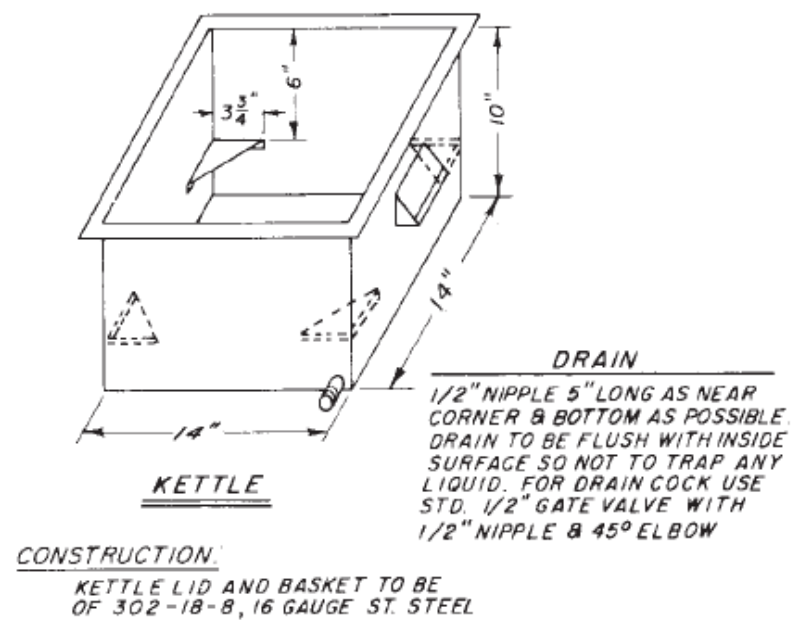

STANO MADE FROM i" $\times i^{\prime \prime} \times i / 8$ " ANGLE IRON

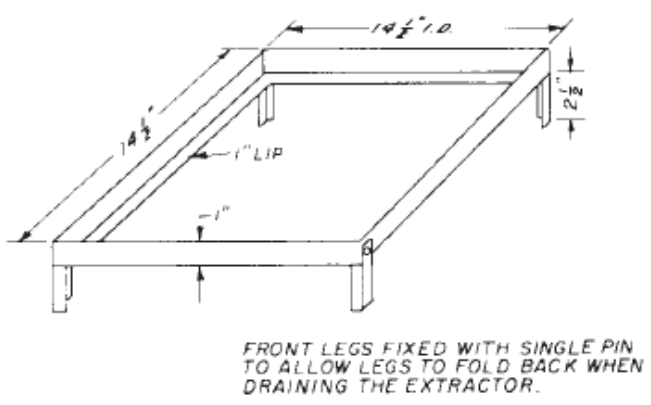

Figure 3. Reflux Extraction Method C (ASTM D 2172) 


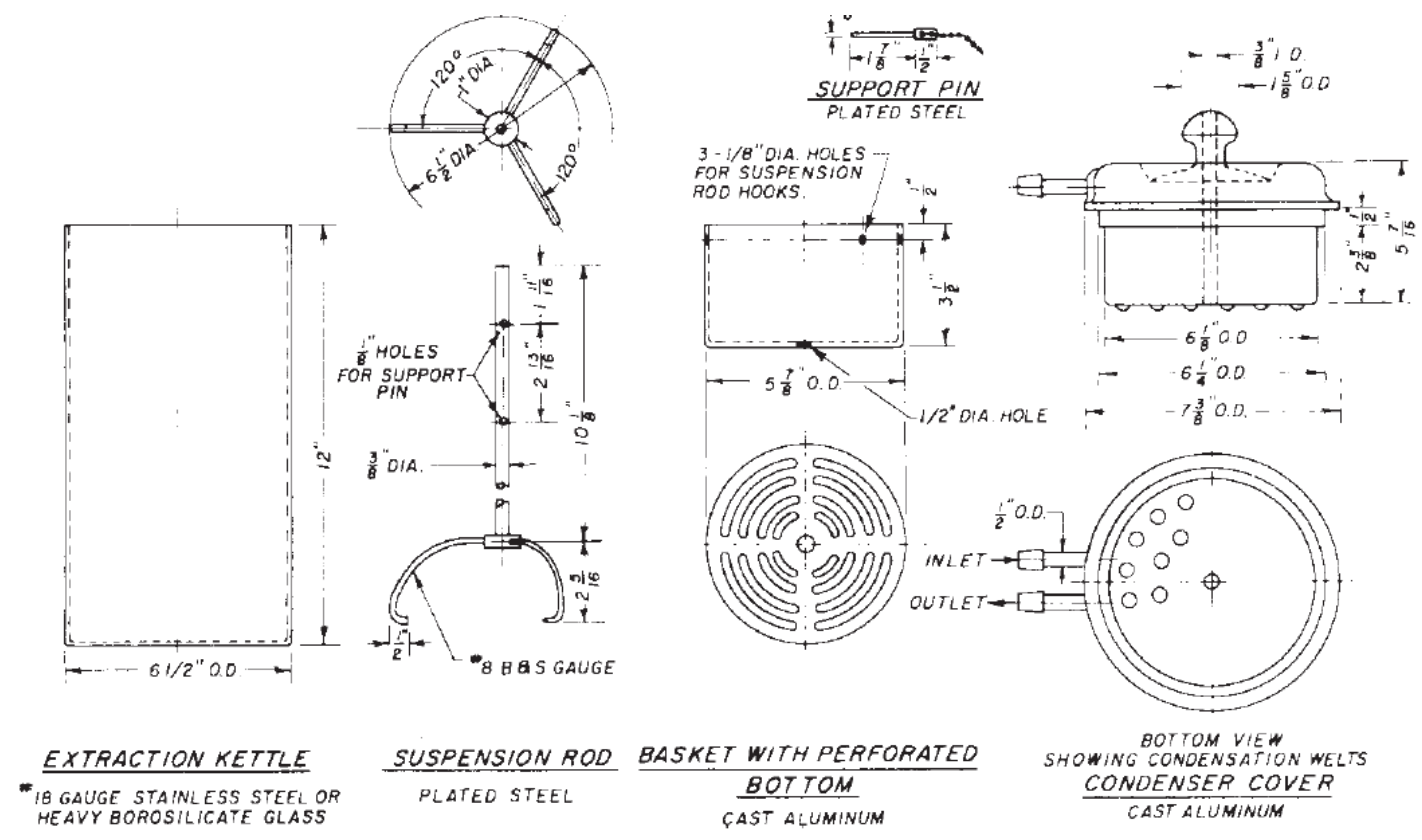

Figure 4. Reflux Extraction Method D (ASTM D 2172)

\section{Vacuum Extraction}

Vacuum extraction (Figure 5, ASTM D 2172 Method E, AASHTO T 164) does not enjoy as widespread use as Centrifuge or even Reflux Extraction [28]. The procedure consists of mixing the solvent and asphalt mixture in the bowl, and then extracting the solvent-asphalt solution with a vacuum pump, with the fines the solvent solution being collected with a series of meshes [27]. Vacuum extraction was found to give the most accurate results for the asphalt binder content when the mixture has highly variable and absorptive aggregates [41]. However, the apparatus has been noted as especially difficult to clean [27], which is likely the reason for its limited use. 


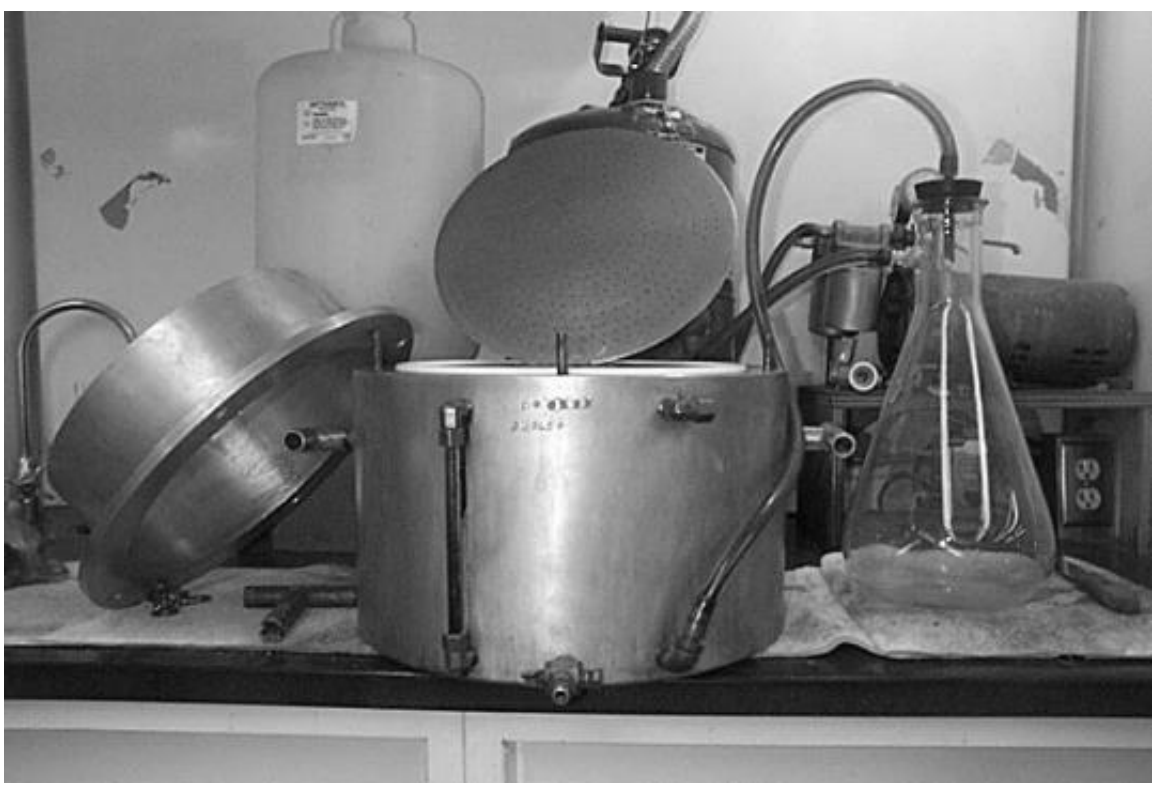

Figure 5. Vacuum Extraction (Iowa Department of Transportation IM 330 [42])

\section{SHRP Extraction}

While studying asphalt binder hardening during extraction and recovery, the SHRP developed a solvent extraction method (originally AASHTO TP2 [43], later redesignated AASHTO T 319 [44] and ASTM D 6847 [45]) which is combined with the Rotovap recovery method (see Recovery Methods). This method was developed to minimize the solvent hardening of the binder, reduce the residual solvent remaining in the binder and be more efficient in removing the binder from the aggregates [13]. Extraction is performed with a rotating cylinder, placed horizontally with interior, flights to mix the asphalt mixture and solvent (Figure 6). A vacuum line with an in-line filter at the bottom of the cylinder removes the effluent and fines are removed with a centrifuge before recovery [33]. 

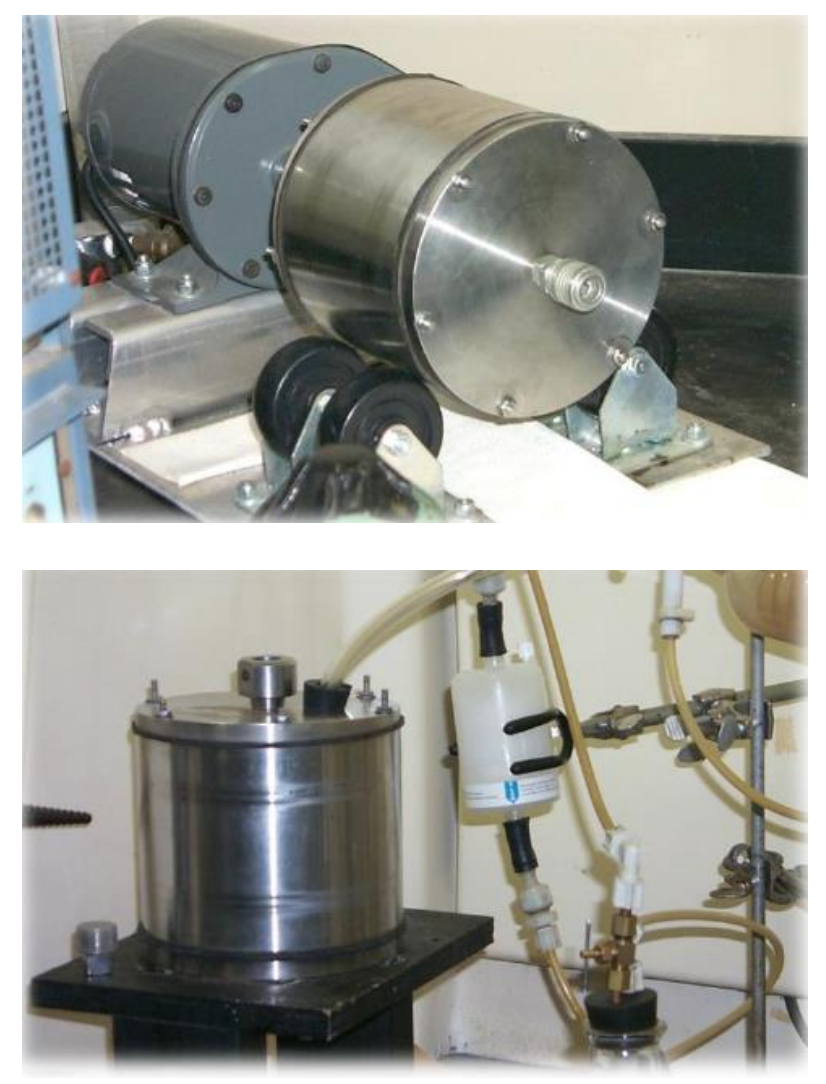

Figure 6. SHRP Extraction Method [46]

The SHRP method was found to remove fines from the extracted solution and the binder from the aggregates better than Centrifuge extraction without the negative effects of the hot Relfux method [33]. Additionally, it was found to be as repeatable in results as the similar Centrifuge-Rotovap method, equally time consuming and comparable in asphalt content determination and gradation [47].

\section{Micro-Extraction}

There has also been a micro-extraction procedure proposed, where a small amount of asphalt is extracted from an asphalt pavement core with a drill. The binder from this sample can then be extracted using a modified AASHTO T 319 procedure [48].

The apparatus is not widely available and that the method remains fairly labour and equipment intensive despite a number of innovations in the method [34]. In fact, the 
ASTM D 6847 standard was withdrawn in 2010, due to the limited number of laboratories being able to perform this method [48].

\section{Automatic Extraction}

There have been a few "automatic" extraction devices developed to perform analysis on asphalt mixtures. The degree that the apparatus is automatized varies, but the goal of these methods is to reduce the amount of labour involved in the test and thereby, lower the labour cost and exposure to toxic chemicals and hot materials by the user. The apparatus may in some way combine one or more of the methods mentioned earlier and comply with standards with EN 12697-1 or ASTM 2172.
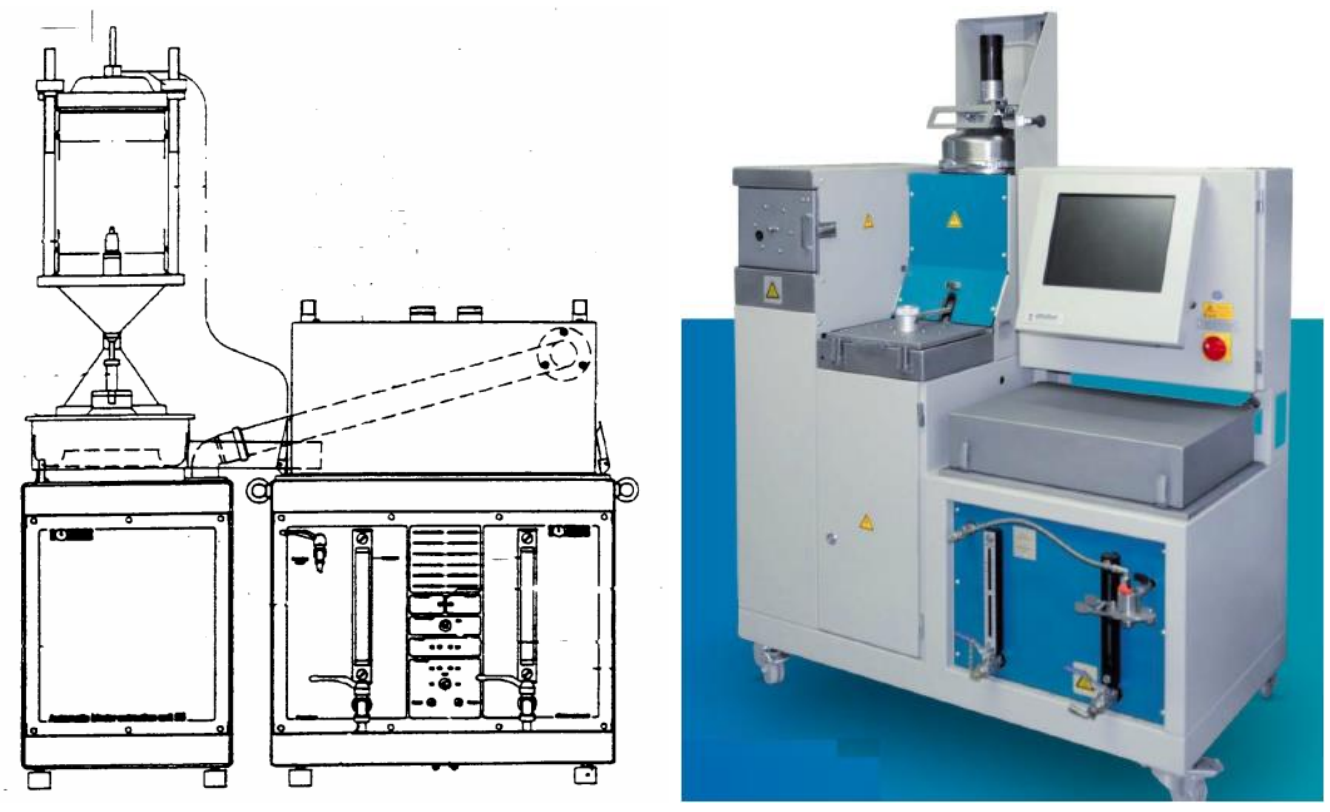

Figure 7. Automatic Extraction Apparatus ([11] left; [49] right)

Monterpara and Giuliani developed an automatic closed-loop apparatus (Figure 7) for binder extraction, with the goal of reducing variability in the determination of asphalt binder content. The extraction is based on the Reflux method (ASTM D 2172 Method B). Cold trichloroethylene is injected into the mixture by an electrically-driven pump, with the flow of solvent controlled. A sieving arrangement separates aggregates from the solvent-binder solution, and the solution is passed through a distiller where the 
binder is recovered or passed through the extractor again. They found that the method was more consistent in determining binder content than the standard reflux method [11].

Elsewhere, an automatic centrifuge was developed with the goal of limiting operator exposure to chlorinated solvents. It was found to obtain results similar to the manual centrifuge in terms of test performance [19]. Currently, automatic extraction devices are available (Figure 7), and have been shown to perform as consistently as centrifuge or reflux based methods and also featured a self-cleaning as part of the apparatus [49]. It has been noted that extraction requires a certain amount of skill, and automating the process addresses this challenge to a large degree [28].

\section{Summary of Extraction Methods}

A summary of the findings for extraction methods is shown in Table 1. Due to their simplicity and prevalence in the industry, Methods A (Centrifuge) and B (Reflux) are the most common. The Centrifuge is a cold method while Reflux is a hot method. Due to the Centrifuge aging the binder significantly less and being safer to operate, it is generally preferred to the Reflux method by researchers performing asphalt extraction for later recovery. The widespread use is advantageous in terms of equipment availability and being able to compare results. Nevertheless, the Reflux is more effective at dissolving the binder than the Centrifuge, and gives more accurate results for binder content. Binders that are difficult to break down, such as those found in RAP, PMA are more likely to need an effective extraction methods such as Reflux. Crumb rubber asphalt remains a challenge, due to the fact that it is difficult to break down [50] and can clog the devices [38].

Table 1. Summary of Asphalt Extraction Methods

\begin{tabular}{|c|c|c|c|}
\hline Method & Temperature & Advantages & Disadvantages \\
\hline
\end{tabular}




\begin{tabular}{llll}
\hline Centrifuge & Room & $\begin{array}{l}\text { Widely used, does not } \\
\text { heat binder }\end{array}$ & $\begin{array}{l}\text { Not as effective at removing } \\
\text { binder from aggregates }\end{array}$ \\
\hline Reflux & Hot & $\begin{array}{l}\text { Effective at removing } \\
\text { binder from aggregates, } \\
\text { more accurate for binder } \\
\text { content }\end{array}$ & $\begin{array}{l}\text { Heats binder causing aging, } \\
\text { heat adds risk for user }\end{array}$ \\
\hline Vacuum & Room & $\begin{array}{l}\text { Good binder content } \\
\text { accuracy with } \\
\text { absorptive aggregates }\end{array}$ & Difficult to clean \\
\hline SHRP & Room & $\begin{array}{l}\text { More effective } \\
\text { extraction than } \\
\text { centrifuge, less aging } \\
\text { than reflux }\end{array}$ & Expensive setup \\
\hline Automatic & Varies & $\begin{array}{l}\text { Safer for user with less } \\
\text { exposure to solvents, } \\
\text { more consistent }\end{array}$ & $\begin{array}{l}\text { Seldom used, various once off } \\
\text { designs, expensive }\end{array}$ \\
\hline
\end{tabular}

Vacuum extraction is relatively less in use, but was found to give the most accurate results for binder content when the mixture had highly variable or absorptive aggregates. The SHRP method is technically the best performing one, having modified centrifuge extraction and being combined with Rotovap recovery. The method was found to eliminate the aging concerns of the Reflux method and be more effective than the Centrifuge. However, due to it being expensive, labour intensive and time consuming, the method is very seldom used.

Finally, there are automatic extraction devices available to reduce labour time and exposure to toxic chemicals for the user. These devices would also have a significant advantage in terms of consistency and require less operator skill.

\section{Recovery Methods}

In order to be able to test the asphalt binder itself after extraction, the binder needs to be separated from the solvent after extraction. Asphalt binder recovery separates the solvent from the binder after the extraction, by a distillation process. During the process, a balance must be achieved between purifying and aging of asphalt binder caused by the excessive exposure to heat during purification [5]. While 
overheating the binder will cause age-hardening effects, it has been shown that just $0.5 \%$ by weight of solvent remaining in the recovered binder could lead to a $50 \%$ decrease in viscosity [17].

\section{Recovery Methods and their Effects}

There are two known methods for the recovery of asphalt binder: (1) the Abson Recovery method, which was introduced in 1933 [51] and (2) the more recent Rotary Evaporation (also called Rotovap), which has been used since the 1970s [52].

Several studies have been performed to evaluate the two recovery methods for their efficiencies. Three main subjects were focused in these studies: i) the ability of the recovery method to discharge the solvent, ii) the effect of these methods on the mechanical characteristics of recovered binder (especially excessive aging due to high temperature used in discharging the solvent) and iii) the human effort needed to perform these methods (more simple methods would lead to more accurate procedures).

\section{Abson Method}

The Abson method (Figure 8) is defined in ASTM D 1856. The solution of solvent and asphalt from extraction is distilled until most of the solvent is gone, then carbon dioxide gas is introduced to remove traces of the solvent in the absence of free oxygen molecules. The purpose of the last part is to prevent the access of oxygen to susceptible hydrocarbons in the asphalt binder structure at elevated temperatures and thus, reducing chemical changes in the recovered asphalt binder.

As the Abson method, was developed in the 1930s [51], it was the only standardized method for decades. However, a number of studies have found evidence of residual solvent in the recovered binder, leading to a recovered binder viscosity reduction of as 
much as $42 \%$ [33]. Other studies have shown a tendency for the Abson Method to be responsible for binder hardening [17]. There have also been repeatability issues reported with the Abson method $[39,53]$, with studies finding very high coefficients of variation for RAP [47] and Pressurized Aging Vessel (PAV, ASTM D 6521) aged binders [18].

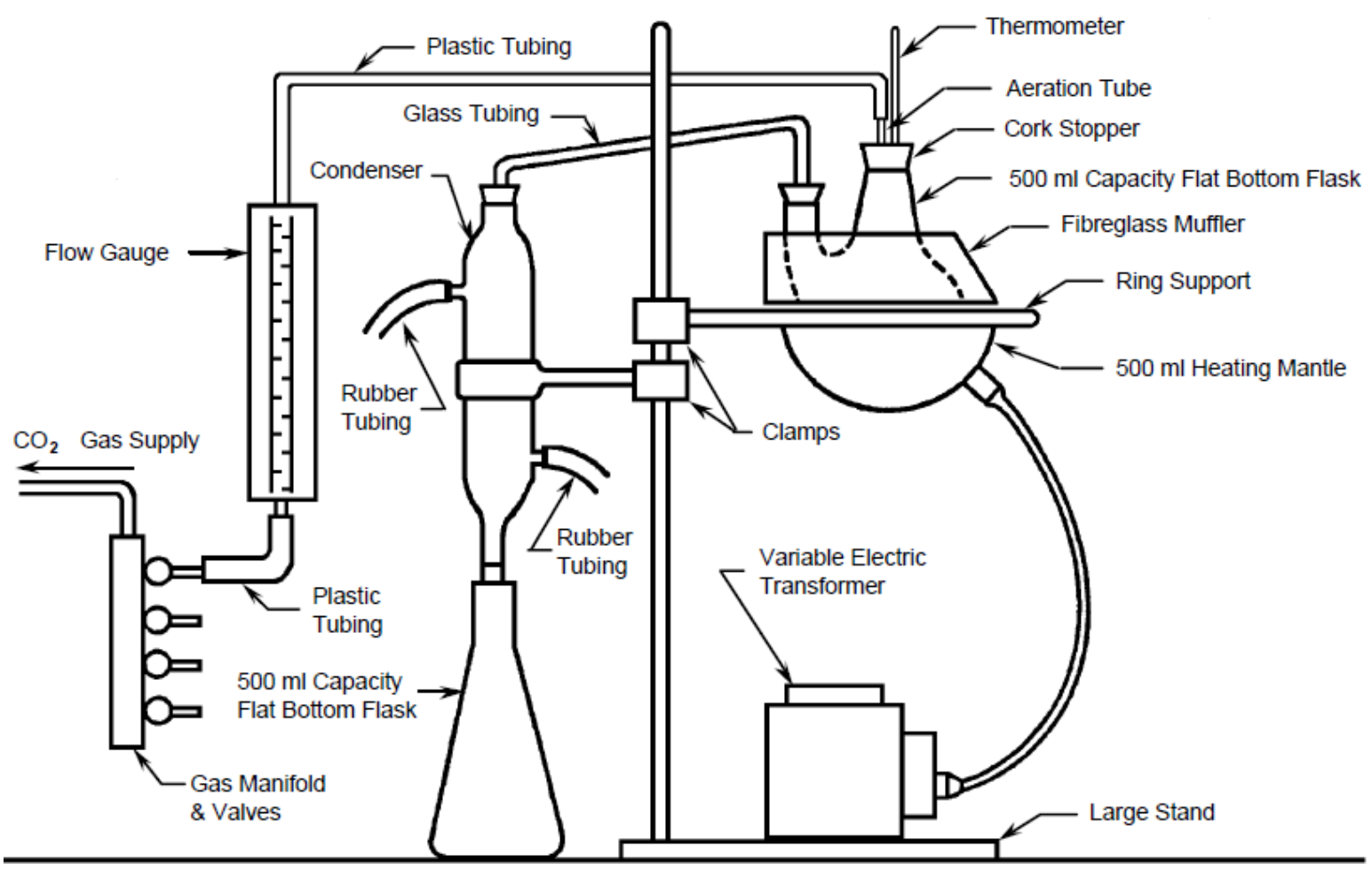

Figure 8. Abson Recovery Distillation System (Ministry of Transportation Ontario MTO LS-284 [54])

\section{Rotary Evaporator}

The rotary evaporator method is described in ASTM D 5404 [55] and EN 12697-3 [56]. This apparatus (Figure 9) includes rotary evaporator, thermometric device, manometer or vacuum gage, gas flowmeter, sample container, vacuum system and oven. The solution of solvent and asphalt binder from the extraction is placed in a rotating flask and distilled by partially immersing the flask in a hot oil bath. The solution is subjected to high vacuum (EN 12697-3) or to partial vacuum and flow of nitrogen gas (ASTM D 5404, AASHTO T 170). The purpose of using nitrogen (and partial vacuum) in this method - is the same as for using carbon dioxide in the Abson 
method - which is to minimize the oxygen access to susceptible hydrocarbons in asphalt binder, limiting the aging in the recovery process.

The Rotovap is considered to have less issues with residual solvent in the recovered binder, especially for high viscosity binder [53]. Additionally, it was found to be more proficient in recovering large sample sizes, be more simple and less labor intensive [52]. It is for these reasons that it was chosen to be the recovery method for SHRP [47].

The Rotovap method was reported to be somewhat less consistent and reproducible than the Abson method [52], although the opposite has been asserted as well [47]. The recovered binder has been said to cause less age-hardening as well due to its reduced temperature at a maximum of $140^{\circ} \mathrm{C}$, as compared to the Abson method, which goes as high as $160^{\circ} \mathrm{C}$ [33]. Studies have nevertheless found a small amount of binder aging by Rotovap for both straight run binders [17] and PMAs [57].

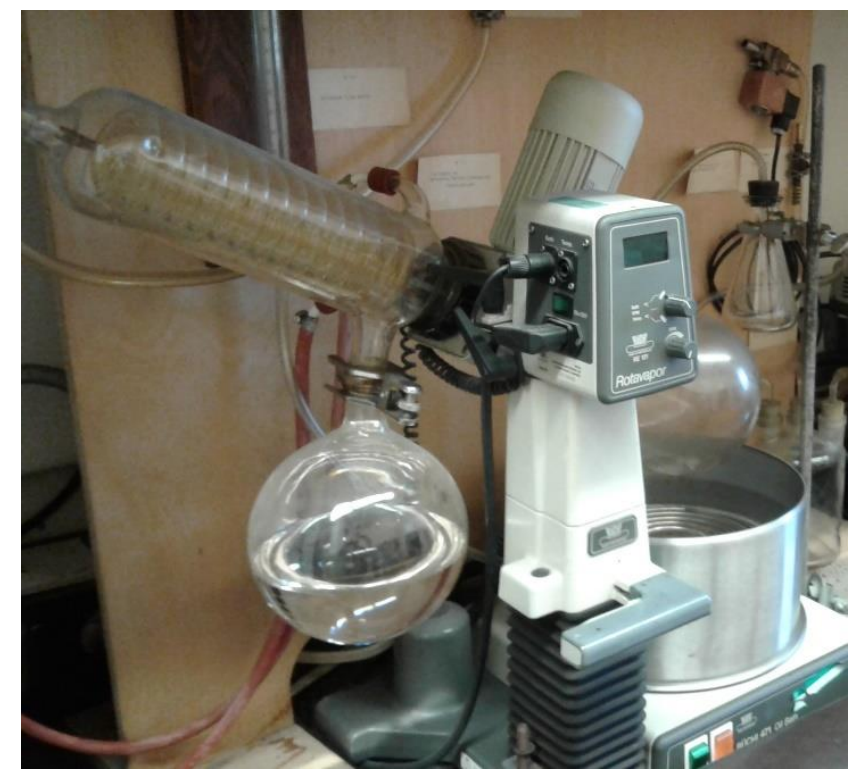

Figure 9. Rotary Evaporator Recovery 


\section{Summary of Recovery Methods}

A summary of the findings on the recovery methods is shown in Table 2. It can be reasoned that both methods can have elevated temperatures and can cause some hardening of binder as found in studies comparing the two methods $[17,18]$. The difference should not be exaggerated as found no change in the PG grade of the recovered binder, compared to the base asphalt binder. Additionally, FTIR analysis found no noticeable chemical changes between the two methods, as well as no significant traces of residual solvent [18].

Table 2. Summary of Asphalt Recovery Methods

\begin{tabular}{llll}
\hline Method & Temperature & Advantages & Disadvantages \\
\hline Abson & Hot & $\begin{array}{l}\text { widely used, } \\
\text { inexpensive }\end{array}$ & binder aging, residual solvent \\
& & improvement & \\
potovap & Hot & aging and residual & \\
& & solvent compared to & \\
& & Abson, less labour & \\
& &
\end{tabular}

Overall, the literature research suggests the use of Rotovap method in lieu of the Abson method due to its capability to provide a greater volume of samples and that fact that it has been found to have less residual solvent after recovery, cause less age-hardening and be easier to operate for the user [34].

\section{Solvents for Asphalt Extraction and Recovery}

The selection of an appropriate solvent for the extraction and recovery of asphalt binder needs to take into account the effectiveness of the solvent in dissolving the asphalt binder during extraction, and the ease of removing the solvent during recovery while not affecting the physical characteristics of the binder. The solvent performance will also depend heavily on the type of binder that is being extracted and recovered. 
Additionally, safety concerns for the operator and environmentally friendliness should be considered.

\section{Solvent Types and their Effects}

Historically, a number of solvents have been used for asphalt binder extraction. Carbon disulfide $\left(\mathrm{CS}_{2}\right)$, was used initially, but was phased out due to high flammability and volatility. Benzene was introduced with the Abson method in the 1930s as a somewhat safer option, and in the 1950s and 1960s, it was replaced by chlorinated solvents [18]. At the time of this study, in addition to chlorinated solvents, n-propyl bromide (nPB) and toluene are commonly used, along with some developments in terms of bio-solvents [28]. Also of note, Xylene $\left[\mathrm{C}_{6} \mathrm{H}_{4}\left(\mathrm{CH}_{3}\right)_{2}\right]$ is a hydrocarbon extraction solvent that has been reported to present significant health risks to users and is not widely employed outside of the Vermont DOT [58].

\section{Chlorinated Solvents}

Although they have primarily been used for cleaning and degreasing [59], chlorinated solvents have been widely used for asphalt extraction and recovery, notably trichloroethylene $\left(\mathrm{CCl}_{2}=\mathrm{CHCl}\right)$, trichloroethane $\left(\mathrm{CH}_{3}-\mathrm{CCl}_{3}\right)$ and dichloromethane (also methylene chloride, $\mathrm{CH}_{2} \mathrm{Cl}_{2}$ ) [53]. These solvents are very effective at dissolving asphalt binder [60] and could be used multiple times, but have significant operator health and environmental concerns. With the banning and phasing out of trichloroethane under the Montreal Protocol in 1996 [61], trichloroethylene has become the most popular solvent for the extraction of asphalt binder [59], with dichloromethane being used as well, but significantly less often. Tetrachloroethylene is a solvent from the chlorinated family, which enjoys popularity in France [62].

There are a good number of Departments of Transportation (DOTs) in the United States 
that have prescribed trichloroethylene (and to a lesser extent dichloromethane) for separation of asphalt binders from asphalt paving mixtures in their quality control programs. However, trichloroethylene remains hazardous to the environment while contributing to the depletion of the ozone layer. Trichloroethylene also poses a danger to humans, having been known to cause headaches, dizziness, and tremors, while exposure to high levels has been known to cause death [52]. Its lipophilic properties give it the potential to absorb through skin and dissolve its protective oils, causing dermatitis [23]. The low boiling point of $87^{\circ} \mathrm{C}$, while being better for binder recovery in having the solvent evaporate quicker, is also a cause for concern from an operator safety perspective. Dichloromethane is considered less toxic to humans [63], although it should be noted that its low boiling point of $40^{\circ} \mathrm{C}$ makes it even more volatile [5].

The use of trichloroethylene is significantly regulated in the United States, with the Environmental Protection Agency (EPA) starting to phase it out in certain industries as of 2016 [64]. In Canada, regulations were passed in 2003 require the metal degreasing industry to decrease consumption of trichloroethylene and tetrachloroethylene $65 \%$ by 2021 [65]. As of 2016, these have been met and $88 \%$ less is consumed annually compared to 2003 [66]. Its use requires significant precautions such as air vents and ventilation masks [67]. In a Note to the LS 282 [68] "Method of Test for Quantitative Extraction of Asphalt Cement and Analysis of Extracted Aggregate from Bituminous Paving Mixtures", the Ministry of Transportation of Ontario announced plans to discontinue the use of chlorinated solvents for extraction testing in quality assurance and referee laboratories starting in 2010 in favour of nPB, although this was not followed through on when concerns were raised about the latter.

As mentioned previously, the performance of an extraction solvent can depend on the type of binder used. Trichloroethylene has been found to result in a higher PG grade for 
recovered RAP binder [69]. It has also been found by FTIR analysis to modify SBS PMA binder during extraction and recovery as well as cause a slight decrease in stiffness and decrease elastic recovery. Dichloromethane has been found to perform better in this regard [40]. For EVA PMA mixtures, trichloroethylene was found preferable to dichloromethane, and both were found to affect the SBS modified binder [12].

\section{n-Propyl Bromide}

Due to the concerns posed by the aforementioned chlorinated solvents, an alternative solvent known as n-propyl bromide $\left(n \mathrm{~PB}-\mathrm{C}_{3} \mathrm{H}_{7} \mathrm{Br}\right)$ was introduced to asphalt extraction and recovery [33] in the 90s, also having previously been used as a degreasing and cleaning solvent [70].

From a performance perspective, it was found to modify binder penetration and viscosity in a similar way to trichloroethylene and could be used for multiple extractions and recoveries with a stabilizer [52]. There may be an issue however, as for trichloroethylene, with acidity in the recycled solvent corroding the extraction equipment, and therefore it is recommended that the acidity of the recycled solvent be monitored and solvent stabilizers used if the acidity is too high [63]. The solvent was also found to work well with RAP binders compared to alternatives [47], although there was some incompatibility found in the case of PMA binders. There have been some issues found the solvent consistency: a comparison from different nPB sources found a variability of around $30 \%$ with the results of different nPB sources testing the same asphalt, [33], indicating a single source must be used when comparing results.

At the time of its introduction in the late $90 \mathrm{~s}, \mathrm{nPB}$ had not been designated a carcinogen. It had however, been found to cause irritation to the lungs, which is 
increased in the case of a pre-existing lung condition. There has also been some skin and eye irritation associated with its use and it was prescribed for use in a wellventilated area to avoid headaches, dizziness and nausea by the user [52]. Like trichloroethylene, $\mathrm{nPB}$ also has the potential to absorb through skin and cause dermatitis [23]. Therefore, it was a less than ideal replacement for chlorinated solvents from the start.

Subsequent concerns have since been raised about nPB as a replacement for chlorinated solvents, as not as much testing had been conducted on nPB previously. Firstly, the testing showed that the vapour pressure for $\mathrm{nPB}$ is higher than for trichloroethylene (110.8 to $58.0 \mathrm{Hg}$ at $20^{\circ} \mathrm{C}$ ), indicating that it is twice as likely to vaporize at room temperature and the boiling point was also lower $\left(71\right.$ to $\left.121^{\circ} \mathrm{C}\right)$. On the other hand, $\mathrm{nPB}$ was found to metabolize in human faster than TCE, indicating it would stay a shorter time in the human body during exposure [23]. However, it was found to have a higher toxicity than dichloromethane [63]. Furthermore, the scent of nPB is lighter that of trichloroethylene, making exposure more difficult to notice for technicians working in the lab.

Overall, the precautions taken when using nPB (personal protective equipment, fume hoods etc.) should be similar to the aforementioned chlorinated solvents. A significant problem occurred when nPB was assumed to be safer than other solvents and it was used in poorly ventilated areas [23]. This mirrored other industries where nPB was introduced, such as in the United States, where its poorly planning introduction has resulted in a significant number of severe workplace injuries [71]. In 2010, chlorinated solvents for extraction and recovery were again allowed by the Ministry of Transportation Ontario in Canada [68], and in 2014, the "U.S. Department of Health and Human Services 13th Report on Carcinogens" classified nPB as a substance 
reasonably anticipated to be a human carcinogen [72].

\section{Toluene}

Toluene $\left(\mathrm{C}_{6} \mathrm{H}_{5}-\mathrm{CH}_{3}\right)$ has been suggested as a solvent that can reduce negative environmental safety and health effects associated with extraction solvents. A study has found that it modifies the binder less than trichloroethylene when tested in the same conditions [73].

With a boiling point of around $110^{\circ} \mathrm{C}$, Toluene is relatively less volatile compared to chlorinated solvents and nPB [18]. The special standard for Rotovap recovery with toluene (ASTM D 7906 [74]) adds some provisions to the normal procedure, including slower flask rotation so that the exposure time is increased.

Generally, some negative health effects may occur with toluene exposure [75], although research suggests that the overall toxicity is low and these effects are reversible even with long term exposure [76]. However, concerns about its flammability have been raised [77] and a spark proof environment is recommended by the Canadian Centre for Occupational Health and Safety [78].

A mixture of $85 \%$ toluene and $15 \%$ ethanol was advised by the SHRP (AASHTO T 319) as the preferred solvent for extraction and recovery, along with nPB [47]. In terms of performance, toluene was found no different in aging the binder than trichloroethylene [79], although, it was found less effective at dissolving binders [60]. On the other hand, when extracting both SBS and EVA PMAs, toluene was found to alter the binder less than chlorinated solvents as well as be more accurate in determining the binder content [12]. 


\section{Bio-Solvents}

With the increasing interest in cost-effective and environmentally friendly chemicals, along with the technology to transform them into useful construction materials, several bio-based solvents have been tested as asphalt binder extraction and recovery solvents [14]. Bio-solvents provide an advantage as they are less toxic to humans and bio-degradable [80], addressing the principal problems of currently used asphalt extraction and recovery solvents. There are disadvantages for using biosolvents, as they are generally used with equipment that is calibrated to certain types of solvents and can be less accurate [14].

The bio-sourced extraction and recovery solvent found in the literature has been dlimonene based, which although having the smell of citrus fruit, is found in certain type of trees and brushes [81]. The commercial version has been found to have a binder content accuracy comparable to trichloroethylene [15], although the extraction time was reported to be longer [58]. Terpene extract has also been mentioned [28], which is derived from cannabis.

Even though bio-sourced chemicals are mostly biodegradable, their disposal costs may still be significant. However, as in the case for d-limonene, which was still classified as hazardous waste, it would be less than for the conventional chlorinated solvents [63].

\section{Summary of Solvents}

A summary of the chemical composition, boiling point and specific gravities of the agents can be found in Table 3. The chlorinated solvents trichloroethylene and dichloromethane are the most prevalent solvents used in asphalt extraction and recovery, along with $\mathrm{nPB}$. Although these are effective solvents and are re-usable, they pose a risk to the user and the environment. 
Table 3. Summary of Asphalt Extraction and Recovery Solvents

\begin{tabular}{|c|c|c|c|c|c|}
\hline Solvent & $\begin{array}{l}\text { Chemical } \\
\text { Designation }\end{array}$ & $\begin{array}{l}\text { Boiling } \\
\text { Point } \\
\left({ }^{\circ} \mathrm{C}\right)\end{array}$ & $\begin{array}{l}\text { Specific } \\
\text { Gravity }\end{array}$ & Advantages & Disadvantages \\
\hline Carbon Disulphide & $\mathrm{CS}_{2}$ & 46.2 & 1.263 & \multirow{2}{*}{ low cost } & \multirow{2}{*}{$\begin{array}{l}\text { flammable } \\
\text { and health } \\
\text { concerns }\end{array}$} \\
\hline Benzene & $\mathrm{C}_{6} \mathrm{H}_{6}$ & 80.1 & 0.879 & & \\
\hline Trichloroethane & $\mathrm{CH}_{3}-\mathrm{CCl}_{3}$ & 74.1 & 1.339 & \multirow{3}{*}{$\begin{array}{l}\text { widely } \\
\text { used, } \\
\text { evaporates } \\
\text { quickly, re- } \\
\text { usable }\end{array}$} & \multirow{3}{*}{$\begin{array}{l}\text { harmful for } \\
\text { users and } \\
\text { environment, } \\
\text { effects on } \\
\text { binder }\end{array}$} \\
\hline Trichloroethylene & $\mathrm{CCl}_{2}=\mathrm{CHCl}$ & 87.0 & 1.464 & & \\
\hline Dichloromethane & $\mathrm{CH}_{2} \mathrm{Cl}_{2}$ & 40.0 & 1.327 & & \\
\hline Toluene & $\mathrm{C}_{6} \mathrm{H}_{5}-\mathrm{CH}_{3}$ & 110.6 & 0.867 & $\begin{array}{l}\text { better for } \\
\text { PMAs, } \\
\text { relatively } \\
\text { safe for } \\
\text { user }\end{array}$ & fire hazard \\
\hline Xylene & $\mathrm{C}_{6} \mathrm{H}_{4}\left(\mathrm{CH}_{3}\right)_{2}$ & 140.0 & 0.864 & & $\begin{array}{l}\text { rarely used, } \\
\text { significant } \\
\text { health risks, } \\
\text { high } \\
\text { evaporation } \\
\text { point }\end{array}$ \\
\hline n-Propyl Bromide & $\mathrm{C}_{3} \mathrm{H}_{7} \mathrm{Br}$ & 71 & 1.354 & $\begin{array}{l}\text { good with } \\
\text { rap, } \\
\text { evaporates } \\
\text { quickly, re- } \\
\text { usable }\end{array}$ & $\begin{array}{l}\text { harmful for } \\
\text { users and } \\
\text { environment, } \\
\text { health } \\
\text { concerns, } \\
\text { corrosive } \\
\end{array}$ \\
\hline $\begin{array}{l}\text { Bio Sourced (d- } \\
\text { Limonene) }\end{array}$ & - & $151-189$ & 0.86 & $\begin{array}{l}\text { green } \\
\text { material }\end{array}$ & $\begin{array}{l}\text { expensive, } \\
\text { high boiling } \\
\text { point, high } \\
\text { quantity } \\
\text { required }\end{array}$ \\
\hline
\end{tabular}

In terms of performance, chlorinated solvents are generally more accurate for straight run binders. On reasons suggested for the effectiveness of chlorinated solvents has been their compatibility with asphalt binders in terms of Hansen solubility parameters [62]. For PMAs, toluene or a mixture of toluene and ethanol provides the best accuracy, as the polymers present a challenge for some solvents. The aging of the binder is a potential issue with all of the mentioned solvents [39], although this depends more on the extraction and recovery apparatus and procedure than on the solvents' composition, particularly on how much heating and pressure is involved. A comparison study has 
shown that both trichloroethylene and toluene do leave solvent in the binder with ASTM recovery procedures [82].

While a d-limonene based solvent has been developed, providing potential improvements in terms of user and environmental safety. They are seldom used, so there is considerable research potential in this regard, especially considering the recent advances in using bio-waste derivatives in construction materials [83], in addition to improving solvent performance.

\section{Conclusions}

This paper studied the state of the art in the extraction and recovery of asphalt binder. Studies on the subject have been primarily dispersed over the past 25 years. Most of the important studies came from United States DOT reports, some Canadian and Belgian reports, while many were in the form journals and conference papers. The studies looked at a wide range of aspects in extraction and recovery, including apparatus, extraction time, ease of operation, user safety, environmental concerns, asphalt binder aging, residual solvent in the binder as well as PMA and RAP recovery, among other aspects. Most of the studies covered a narrow aspect of extraction and recovery, with a few exceptions.

\section{Extraction Methods}

Due to their simplicity and prevalence in the industry, Centrifuge and Reflux Method B are the most common extraction methods. The Centrifuge is a cold method while Reflux is a hot method. Due to the Centrifuge aging the binder significantly less and being safer to operate, it is generally preferred to the Reflux method by researchers performing both extraction and recovery. The Reflux is more effective at dissolving the binder than the Centrifuge, and gives more accurate results for binder content. 
Vacuum extraction is seldom used, but was found to give the most accurate results for binder content when the mixture had highly variable and absorptive aggregates. The SHRP method is technically the best performing one, found to eliminate the aging concerns of the Reflux method and be more effective than the Centrifuge. However, due to it being expensive, labour intensive and time consuming, the method is relatively seldom used. Finally, there have been a number of "automatization" modifications on extraction tests that serve to reduce labour time and exposure to toxic chemicals for the user.

\section{Recovery Methods}

For the recovery methods, the Rotovap method is preferred by researchers over the Abson method because of its capability to provide a greater volume of sample, having less residual solvent after recovery, causing less age-hardening, and being easier to operate for the user.

\section{Solvents}

The chlorinated solvents trichloroethylene and dichloromethane are the most prevalent solvents used in asphalt extraction and recovery, along with $\mathrm{nPB}$. These solvents are reusable for multiple extractions. However, they both pose significant health and safety risks.

Toluene is safer relative to chlorinated solvents in terms of operator health but is more dangerous due to being highly combustible. For PMAs, toluene or a mixture of toluene and ethanol provides the best accuracy, as the polymers present the challenge of the polymer dissolution.

The aging of the binder is a potential issue with all of the mentioned solvents, although 
this depends more on the extraction and recovery apparatus and procedure than on the solvent composition, particularly on how much heating is involved. The health and safety dangers remain the biggest issue with solvents. Only two bio-sourced agents have been found in the literature to have been used as extraction and recovery solvents, $d$ limonene and terpene extract, which are seldom used.

\section{Recommendations}

The current literature study of asphalt binder extraction and recovery has revealed a number of opportunities for improvement in these methods. Overall, the SHRP method appears to be the best performing one. It is very labour and equipment intensive however, and further study to simplify the process as well as ministry promotion of it could encourage more laboratories to employ it.

The Centrifuge is the preferred extraction method among researchers and laboratories. Improvements in this method could be made if it was made more effective in separating the asphalt from the aggregates. The Rotovap is the preferred recovery apparatus, and is not likely to need any improvements, although more automation might improve the safety from a user perspective. In fact, an automated apparatus with centrifuge and Rotovap would be desirable and becoming available. However, more studies need to be done on the quality of the recovered binder, particularly of modified one such as PMA, to determine if these types of binder are modified by the process significantly.

The most common solvents are trichloroethylene and nPB. Both products are hazardous to the user and the environment here is likely where the most innovation is needed. Biosolvents in various industrial spheres have been around for decades, however, little research has been performed on them. With the bio-technology and resources available today, a bio-sourced extraction and recovery solvent that has improved or comparable 
performance to the currently used solvents would be an important study, especially from the crucial user safety and environmental perspective.

\section{References}

[1] AASHTO T 315 - Standard Method of Test for Determining the Rheological Properties of Asphalt Binder Using a Dynamic Shear Rheometer (DSR), American Association of State Highway and Transportation Officials (2017).

[2] ASTM D 46 - Standard Test Method for Softening Point of Bitumen (Ring-and-Ball Apparatus), American Society for Testing and Materials (2014).

[3] ASTM D 5 - Standard Test Method for Penetration of Bituminous Materials, American Society for Testing and Materials (2013).

[4] AASHTO T 313 - Determining the flexural creep stiffness of asphalt binder using the bending beam rheometer (BBR), American Association of State Highway and Transportation Officials (2017).

[5] J. Huet, Recovery method with rotary evaporator of the soluble binder from bituminous mixes: interlaboratory test comparisons and test procedure recommendation, Materials and Structures. 21 (1988) 151-160. doi:10.1007/BF02472851.

[6] M. Zargar, E. Ahmadinia, H. Asli, M.R. Karim, Investigation of the possibility of using waste cooking oil as a rejuvenating agent for aged bitumen, Journal of Hazardous Materials. 233-234 (2012) 254-258. doi:10.1016/j.jhazmat.2012.06.021.

[7] A. Copeland, Reclaimed asphalt pavement in asphalt mixtures: state of the practice, Federal Highway Administration, 2011.

[8] I.L. Al-Qadi, M. Elseifi, S.H. Carpenter, Reclaimed Asphalt Pavement - A Literature Review, Illinois Center for Transportation, Urbana, IL, 2007.

[9] T. Baghaee Moghaddam, H. Baaj, The use of rejuvenating agents in production of recycled hot mix asphalt: A systematic review, Construction and Building Materials. 114 (2016) 805-816. doi:10.1016/j.conbuildmat.2016.04.015.

[10] B. Huang, G. Li, D. Vukosavljevic, X. Shu, B. Egan, Laboratory investigation of mixing hot-mix asphalt with reclaimed asphalt pavement, Transportation Research Record: Journal of the Transportation Research Board. (2005) 37-45.

[11] A. Monterpara, F. Giuliani, Control of binder content in bituminous mixes by means of an automatic apparatus, in: TRANSCOM '99, Zilina, Slovakia, 1999.

[12] N. Piérard, S. Vansteenkiste, A. Vanelstraete, Effect of Extraction and Recovery Procedure on the Determination of PmB Content and on the Properties of the Recovered Binder, Road Materials and Pavement Design. 11 (2010) 251-279. 
[13] S. Kim, T. Byron, G.A. Sholar, J. Kim, Evaluation of Use of High Percentage of Reclaimed Asphalt Pavement (RAP) for Superpave Mixtures, Florida Department of Transportation, 2007.

[14] E.R. Brown, N.E. Murphy, S. Mager, L. Yu, Historical development of asphalt content determination by the ignition method, Asphalt Paving Technology. 64 (1995) 241-277.

[15] M.S. Sondag, B.A. Chadbourn, A. Drescher, Investigation of Recycled Asphalt Pavement (RAP) Mixtures, University of Minnesota, Minneapolis, MN, 2002.

[16] B.L. Burr, R.R. Davison, H.B. Jemison, C.J. Glover, J.A. Bullin, Asphalt Hardening in Extraction Solvents, Transportation Research Record. (1991) 70-76.

[17] R.L. Peterson, H.R. Soleymani, R.M. Anderson, R.S. McDaniel, Recovery and Testing of RAP Binders from Recycled Asphalt Pavements, in: 78th Annual Meeting of the Transportation Research Board, Washington, DC, 1999.

[18] S.D. Diefenderfer, Developing a Laboratory Protocol for Asphalt Binder Recovery, Virginia Center for Transportation Innovation and Research, 2014.

[19] N. Piérard, A. Vanelstraete, Quid de la mesure de la teneur en liant par extraction au solvant dans le cas des liants bitumineux modifiés aux polymères et des liants pigmentables, in: Congrès Belge de La Route, Liege, Belgium, 2013.

[20] H. Baaj, P. Dorchies, D. Perraton, B. Tessier, Module complexe et comportement à basse température des enrobés bitumineux modifiés aux bardeaux d'asphalte, in: Proceedings of the Canadian Technical Asphalt Association Conference, 2004: pp. $315-240$.

[21] D. Swiertz, E. Mahmoud, H. Bahia, Estimating the effect of recycled asphalt pavements and asphalt shingles on fresh binder, low-temperature properties without extraction and recovery, Transportation Research Record: Journal of the Transportation Research Board. (2011) 48-55.

[22] O. Sirin, M. Tia, Investigation of problems in binder extraction from conventional and rubber modified asphalt mixtures, in: Sixth International RILEM Symposium on Performance Testing and Evaluation of Bituminous Materials, RILEM Publications SARL, 2003: pp. 212-219.

[23] D. Bechtel, A Short Review of 1-Bromopropane Literature and Contrast to Trichloroethylene Use in Aggregate Analysis, PRTox Consulting Inc., 2012.

[24] A. Andriescu, T. Arnold, N. Gibson, A. Shastry, S. Needham, S. Parobeck, Development of an Asphalt Binder Solvent Recovery Method as an Alternative to Rotovapor ASTM D 5404, FHWA Turner-Fairbank Highway Research Center, 2016.

[25] G.W. Steele, F.L. Krieger, Statistical Evaluation of Equipment and Operator Effects on the Results of Asphalt Extraction Tests, in: Assoc Asphalt Paving Technol Proc, 1967. 
[26] ASTM D 2172 - Quantitative Extraction of Bitumen from Bituminous Paving Mixtures, American Society for Testing and Materials (2011).

[27] A. Norton Jr, High Reclaimed Asphalt Pavement in hot mix asphalt, Master's Thesis, Rowan University, 2012.

[28] P. Mikhailenko, H. Baaj, Survey of Current Asphalt Binder Extraction and Recovery Practices, in: 2017 Transportation Association of Canada Conference, St. John's, Canada, 2017.

[29] EN 12697-1 - Bituminous mixtures. Test methods for hot mix asphalt. Soluble binder content, European Committee for Standardization (CEN) (2012).

[30] AASHTO T 164 - Standard Method of Test for Quantitative Extraction of Asphalt Binder from Hot Mix Asphalt (HMA), American Association of State Highway and Transportation Officials (2014).

[31] ASTM D 1856 - Standard Test Method for Recovery of Asphalt From Solution by Abson Method, American Society for Testing and Materials (2009).

[32] D.E. Carey, H.R. Paul, Evaluation of asphalt cement extraction and recovery methods, Louisiana Department of Transportation, 1982.

[33] M. Stroup-Gardiner, J.W. Nelson, Use of normal propyl bromide solvents for extraction and recovery of asphalt cements, National Center for Asphalt Technology, 2000.

[34] Y. Mehta, A. Nolan, S. Coffey, Eric Du Bois, A. Norton, D. Reger, P. Shirodkar, K. Sonpal, C. Tomlinson, High Reclaimed Asphalt Pavement In Hot Mix Asphalt, Rowan University, 2012.

[35] N. Piérard, Quid de l'extraction et de la récupération des liants modifiés au polymère d'enrobés bitumineux? Les procédures classiques sont-elles toujours applicables?, Bulletin CRR. (2011) 12-16.

[36] S. Varamini, S.L. Tighe, Effect of Coloring Pigment on Asphalt Mixture Performance: Case for Use in Ontario, in: Transportation Research Board 95th Annual Meeting, Washington, DC, 2016.

[37] J.-P. Planche, Insights into binder chemistry, microstructure, properties relationships \& usage in the real world, in: ISAP 2014, CRC Press, Raleigh, USA, 2014: pp. 13-20.

[38] H. Collins-Garcia, T. Mang, R. Roque, B. Choubane, An evaluation of an alternative solvent for extraction of asphalt to reduce health and environmental hazards, in: 79th Annual Meeting of the Transportation Research Board, Washington, DC, 2000.

[39] H.U. Bahia, D. Swiertz, Design System for HMA Containing a High Percentage of RAS Material, University of Wisconsin, Madison, Wisconsin, 2011. 
[40] N. Piérard, A. Vanelstraete, Extraction et récupération des bitumes modifiés aux polymères (SBS, EVA) contenus dans les enrobés bitumineux sur base des normes d'essai EN 12697-1 et -3, in: Congrès Belge de La Route, Ghent, Belgium, 2009.

[41] L.E. Tibbits, Implementation of the Vacuum Extraction Method for the Determination of Asphalt Binder Content, Michigan Department of Transportation, 2005.

[42] IM 330 - Test method for determining the bitumen content of asphalt paving mixtures by the use of the vacuum extractor, (2006).

[43] AASHTO TP2 - Standard Test Method for the Quantitative Extraction and Recovery of Asphalt Binder from Asphalt Mixtures, American Association of State Highway and Transportation Officials (2001).

[44] AASHTO T 319 - Standard Method of Test for Quantitative Extraction and Recovery of Asphalt Binder from Asphalt Mixtures, American Association of State Highway and Transportation Officials (2015).

[45] ASTM D 6847 - Standard Test Method for Quantitative Extraction and Recovery of Asphalt Binder from Asphalt Mixtures, American Society for Testing and Materials (2002).

[46] M. Anderson, Introduction to Asphalt Extraction/Recovery Procedures, in: Recovery Procedures and Testing of Recovered Asphalt Binders Seminar Hosted by the Technical Advisory Committee, Montreal, Quebec, 2017.

[47] R.S. McDaniel, H. Soleymani, R.M. Anderson, P. Turner, R. Peterson, Recommended use of reclaimed asphalt pavement in the Superpave mix design method, National Cooperative Highway Research Program, 2000.

[48] M.J. Farrar, R.W. Grimes, S. Wiseman, J.-P. Planche, Asphalt Pavement-Microsampling and Micro-extraction Methods, Western Research Institute, 2015.

[49] S. Glidden, Automated Extraction of Asphalt Binder, in: Asphalt Binder Expert Task Group, Ames, Iowa, 2017.

[50] M. Heitzman, Design and construction of asphalt paving materials with crumb rubber modifier, Transportation Research Record. 1339 (1992).

[51] G. Abson, Method and Apparatus for the Recovery of Asphalt, in: ASTM Proceedings, 1933: pp. 704-714.

[52] H. Collins-Garcia, M. Tia, R. Roque, B. Choubane, Alternative solvent for reducing health and environmental hazards in extracting asphalt: An evaluation, Transportation Research Record: Journal of the Transportation Research Board. (2000) 79-85.

[53] B.L. Burr, R.R. Davison, C.J. Glover, J.A. Bullin, Solvent Removal from Asphalt, Transportation Research Record. (1990) 1-8. 
[54] LS 284 - Method of test for recovery of asphalt from solution by Abson or Rotavapor, Ministry of Transportation, Ontario Test Method (1996).

[55] ASTM D 5404 - Standard Practice for Recovery of Asphalt from Solution Using the Rotary Evaporator, American Society for Testing and Materials (2012).

[56] EN 12697-3 - Bituminous mixtures. Test methods. Bitumen recovery: Rotary evaporator, European Committee for Standardization (CEN) (2013).

[57] J. McGraw, E. Johnson, G. Johnson, S. Dai, D. Linell, M. Watson, Incorporation of recycled asphalt shingles in hot-mixed asphalt pavement mixtures, Minnesota Department of Transportation, 2010.

[58] T. Houser, Bitumen extraction from asphalt pavements, US 5053118 A, 1991.

[59] R.E. Doherty, A History of the Production and Use of Carbon Tetrachloride, Tetrachloroethylene, Trichloroethylene and 1,1,1-Trichloroethane in the United States: Part 2-Trichloroethylene and 1,1,1-Trichloroethane, Environmental Forensics. 1 (2000) 83-93. doi:10.1006/enfo.2000.0011.

[60] P. Mikhailenko, G. Webber, H. Baaj, Evaluation of solvents for asphalt extraction, Road Materials and Pavement Design. (2019). doi:10.1080/14680629.2019.1661277.

[61] UN Ozone Secretariat, The Montreal protocol on substances that deplete the ozone layer, in: United Nations Environment Programme, Nairobi, Kenya, 2000.

[62] L. Ziyani, L. Boulangé, A. Nicolaï, V. Mouillet, Bitumen extraction and recovery in road industry: A global methodology in solvent substitution from a comprehensive review, Journal of Cleaner Production. 161 (2017) 53-68. doi:10.1016/j.jclepro.2017.05.022.

[63] J. McGraw, D. Iverson, G. Schmidt, J. Olson, Selection of an alternative asphalt extraction solvent, Minnesota Department of Transportation, 2001.

[64] US EPA, Trichloroethylene Fact Sheet, (2016).

[65] Federal-Provincial Advisory Committee on Environmental and Occupational Health (Canada), ed., Exposure guidelines for residential indoor air quality: a report of the Federal-Provincial Advisory Committee on Environmental and Occupational Health, Rev, Health and Welfare Canada, Ottawa, Ont, 1989.

[66] Tetrachloroethylene, Carex Canada (2016).

[67] Toxicological Profile for Trichloroethylene (TCE), Agency for Toxic Substances and Disease Registry, 2015.

[68] LS 282 - Method of test for quantitative extraction of asphalt cement and analysis of extracted aggregate from bituminous paving mixtures, Ministry of Transportation, Ontario Test Method (2010). 
[69] Z. Hossain, P. Solanki, M. Zaman, D. Adje, S. Lewis, Test Methods For Use of Recycled Asphalt Pavement in Asphalt Mixes, College of Engineering, University of Oklahoma, 2012.

[70] L. Clark, EnSolv Vapor Degreasing and Cleaning Solvent, (1998).

[71] I. Urbina, As OSHA Emphasizes Safety, Long-Term Health Risks Fester, The New York Times. (2013).

[72] National Toxicology Program, 13th Report on carcinogens, US Department of Health and Human Services, Research Triangle Park (NC), 2014.

[73] S.-W. Loh, J. Olek, Contributions of PG graded asphalt to low temperature cracking resistance of pavement, Purdue University Department of Civil Engineering, 1999.

[74] ASTM D 7906 - Standard Practice for Recovery of Asphalt from Solution Using Toluene and the Rotary Evaporator, American Society for Testing and Materials (2012).

[75] B. Va, Health effects of toluene: a review., Neurotoxicology. 2 (1981) 567-588.

[76] A.K. Low, J.R. Meeks, C.R. Mackerer, Health Effects of the Alkylbenzenes. I. Toluene, Toxicology and Industrial Health. 4 (1988) 49-75. doi:10.1177/074823378800400105.

[77] M. Glor, A Synopsis of Explosion Hazards During the Transfer of Powders into Flammable Solvents and Explosion Preventative Measures, Pharmaceutical Engineering. 30 (2010) 56.

[78] T.S.S. Dikshith, Handbook of Chemicals and Safety, CRC Press, 2016.

[79] C.A. Cipione, R.R. Davison, B.L. Burr, C.J. Glover, J.A. Bullin, Evaluation of solvents for extraction of residual asphalt from aggregates, Transportation Research Record. (1991) 47-52.

[80] Y. Gu, F. Jérôme, Bio-based solvents: an emerging generation of fluids for the design of eco-efficient processes in catalysis and organic chemistry, Chem. Soc. Rev. 42 (2013) 9550-9570. doi:10.1039/C3CS60241A.

[81] A. Falk Filipsson, J. Bard, S. Karlsson, Limonene, World Health Organization, Geneva, 1998.

[82] T. Bennert, Discussion of 2015 ASTM Binder Recovery ILS, in: Recovery Procedures and Testing of Recovered Asphalt Binders Seminar Hosted by the Technical Advisory Committee, Montreal, Quebec, 2017.

[83] P. Mikhailenko, Valorisation of by-products and products from agro-industry for the development of release and rejuvenating agents for bituminous materials, $\mathrm{PhD}$ Thesis, Universite Paul Sabatier Toulouse III, 2015. 